\title{
SPECIFy THE SPIRAL
}

\author{
Gwyn Miles
}

The Victoria and Albert Museum (V\&A) is the largest decorative arts museum in the world. The unrivalled collections, which have developed over the last 150 years and which continue to grow apace, are housed within a complex of Grade 1 listed buildings in South Kensington. These buildings, started in the 1850s and completed by Aston Webb in 1909, are an important part of the Museum experience. They encompass seven miles of galleries in which the public may encounter diverse collections: these include ceramics, dress, furniture, glass, jewellery, metalwork, photographs, paintings, sculpture and textiles drawn from Europe and Asia.

However, the Museum is more than just its collections. It is a unique international resource for design which belongs to the people of the United Kingdom and the World. Unlike many museums that grew from a founder's collection, the V\&A was developed as a great idea, an educational experiment to improve the design education of all classes of the community and to inspire the designers of the day as an attempt to raise the standards of British manufacturing. The mission of our founders - to help people appreciate the quality of the everyday objects they make and use - remains as important and relevant today.

At the close of the 20th century, one of the major challenges for the V\&A was to make this rich, eclectic collection available to the public in an interesting and informative manner. Over time the galleries had become increasingly difficult to navigate and the dis- plays less and less relevant to successive generations. To navigate the sources of information which are relevant to art and design required the use of new techniques and technologies. What was needed was a learning centre in which we could encourage re-interpretation of art, craft and design through a variety of methods and explanation. A place where meanings and functions of art and design could be explored.

By 1995, the V\&A had completed a major overhaul of its building fabric. The roofs had been mended to the point that they no longer leaked uncontrollably, the wiring had been replaced, drainage overhauled and a modern fire detection system installed throughout. The buildings were now safe and secure, although they will always require dedicated maintenance to keep it in good repair. At this stage it was possible to envisage major de- 
68 velopments to radically improve the display of the collections.

In that year the Museum embarked on the complete re-working of their British Galleries. These galleries which extended over $10 \%$ of the display space of the Museum were to trace the evolution of British design from $1500-1900$. They were tackled in a completely new way by the project team, which included from the outset curators, historians and educators. The galleries were specifically designed not only to be a glamorous and evocative display of the exceptional collections, but also to engage all types of learner: from the specialist to the interested adult, from the scholar to the schoolchild. The emphasis on different methods of interpretation in these galleries, which opened in 2001, was a new departure for the V\&A and has been conspicuously successful, both in terms of numbers of visitors to the galleries and its critical reception by other museum professionals.

At the same time the V\&A had another pressing problem. Its engagement with the contemporary was completely invisible. Ever since its foundation in the mid nineteenth century, the Museum has collected not only examples of art and design from the past, but also objects of recent manufacture. However, the layout of the galleries did not reflect this, with a relatively small area devoted to 20th century design and only intermittent displays on contemporary artists and practitioners. The V\&A gave the impression of looking backwards rather than forwards, not helped by the loss of 'the Boilerhouse' project - a series of innovative temporary exhibitions on the former site of the earlier Museum boilerhouse.

\section{Boilerhouse COMPETITION}

There was a determination to re-establish the V\&A as a centre for innovation where everyone could participate in art and design. The Boilerhouse site was the one area on the plan which had been identified as suitable for an extension. The irregular shaped site sits on the Exhibition Road frontage, between buildings completed in 1874 on one side and 1909 on the other. The purpose of a development on the site was first and foremost to provide a platform for contemporary displays, but equally important was the need for orientation for the whole Museum and a desire to use innovative methods of communication and interpretation.

An international competition was held between December 1995 and May 1996 to select the design team for the new development. A competition brief was drawn up and eight practices asked to prepare an initial concept for the building.

The brief called for a new entrance and linkages to the existing buildings.

The new entrance must provide generous public spaces, for orientation, for meeting and for congregating, and in order to provide a nucleus from which various explorations and activities can radiate. ...The entrance should provide clear directions to move further into the building particularly to education and orientation spaces. Careful consideration should also be given to the interlocking of spaces, for instance how education and exhibition spaces could work together.

Flexible display space was the absolutely requirement of the brief:

a high degree of flexibility is essential in the display spaces, thus providing the potential to accommodate very different kinds of material and exhibitions of lar- 
ge or small scale. The basic structure of the gallery spaces should be defined by substantial walls, within these larger spaces a degree of flexibility should be provided through the use of good quality temporary walls capable of combinations and division on a modular basis... The exhibition areas are required to have flexible servicing throughout. All exhibition areas are required to have robust finishes. Views are desirable because they give relief to the eye. Though display spaces need not be standard, it is important that an overall coherence of design should be maintained and that public areas outside the display areas should also be places where works of art can be comfortably located.

The new building was seen as a powerhouse for the entire Museum and should provide three elements:

It should revolutionise the museum-going experience bringing a powerful new meaning to museology. Using interactive technologies already at our disposal combined with innovative and challenging displays and workshops it will provide a new experience in museum visiting. Visitors will be able to participate in the creative process while benefiting from the cultural memory stored within this great institution.

It will be the first 21 st century building on the V\&A site. Built and decorated using experimental techniques and materials, the Museum has a tradition of using contemporary craftsmen to provide inspiring spaces for cultural activity. The new extension should continue this tradition as far as possible.

It should provide a new social space, taking down the barriers between the grand Victorian institutional façade and the people. The new building should open the V\&A up to the street, providing a range of visitor facilities to be used freely and re-animate the area of Albertopolis.

The eight architectural practices who prepa- red initial concepts for the site were: Benson

\& Forsythe, Norman Foster \& Partners, Nicholas Grimshaw, Zaha Hadid, Michael Hopkins \& Partners, Eva Jiricna, Ian Ritchie and Daniel Libeskind in collaboration with Cecil Balmond. The panel unanimously selected Daniel Libeskind as the leader of the design team as we felt that his proposal for a building, 'the Spiral', best addressed the requirements of the brief. An exhibition of the eight proposals was displayed between June and August of 1996 at the V\&A.

\section{Development of THE Designs}

A feasibility study (Architectural Stage B), completed by January 1997, was presented to the Royal Fine Art Commission. They approved the scheme with the commendation: 'the Spiral is a daring and innovative structure. (which will) relieve the monotony of Exhibition Road without being unduly dominant'. Even more encouraging was the response of the English Heritage Commissioners in February 1997, who unanimously approved the building. The Chairman of English Heritage, Sir Jocelyn Stevens, commented: 'Perhaps we are witnessing a watershed in public taste when design quality of this kind is appreciated and greeted so enthusiastically.'

As the design team worked with the V\&A to develop the plans for the building there were extensive consultation meetings with the planning authorities and English Heritage. Local residents were invited in on a regular basis to see the plans taking shape and presentations were given to local amenity groups, the Victorian Society and the 20th Century Society. Support was polarised between some vocal groups who were against such a modern intervention and high levels of support and 
70 praise from the heritage and arts constituencies.

In order to gain insight into the attitudes across the entire range of local residents, a research exercise was conducted by MORI in June 1998. A representative sample of residents living in Kensington and Chelsea showed that support outweighed opposition to the construction of the Spiral (49\% against 34\%). Interestingly almost eight in ten residents said that they would visit the Spiral once open. Another interesting finding was that of those who originally opposed the building, $10 \%$ had changed their minds and were in favour of it. This survey encouraged the project team as the scheme was progressing through its planning application. The Royal Borough of Kensington \& Chelsea approved the scheme in November in 1998.

\section{DESCRIPTION OF THE BUILDING}

The superstructure of the building is simple and elegant, a series of inclined leaning plates intersect to form a self-supporting spiral. The walls overlap and interlock in a strong, robust manner that gives the structure its stability and allows it to stand free of its own accord, needing no additional core or brace. The flat floors span between the walls and are column free, allowing maximum flexibility of use. The concrete walls will be clad in large ceramic tiles. Three different shapes will be used, drawing on classical ideas of proportion. These three shapes will interlock in an infinite variety of ways to create an intriguing fractal pattern. The tiles will be of one basic colour chosen to complement the stone of the surrounding museum buildings and textured to add vitality to the façade walls.

Beneath the Spiral superstructure will be a basement plant room. Above this at the start of the Spiral itself there will be two entrance floor levels, one at the same level as the tunnel from the underground station (South Kensington) and the other on the level of the Exhibition Road pavement. The entrance at this level will be a generous ramp leading from the pavement into the Spiral. A flight of steps will lead down to the forecourt café and entrance, where it will be possible to walk around the building and gain access to the adjacent Learning Centre.

As the second major entrance to the V\&A these two levels together will act as the key to unlock the Museum. Imaging technology will be used to provide interactive guides to the galleries and collections both in the Spiral and the main Museum. Visitors will be able to plan personalised tours, and will then be guided through the Museum, able to access any background material relevant to the exhibits on their chosen route. At both levels there will be direct lift access to all floors of the Spiral and at the upper entrance level is the major route into the main Museum. Visitors will progress directly into the heart of the new welcome zone of the museum - a cloister running around the garden.

Above the two entrance levels will be five floors of gallery space. Each floor will have a distinctive character and use. The functionality of the spaces has been intensively tested through the use of a 1:20 model. This has allowed us to mock up exhibition ideas and has demonstrated how displays can be mounted in what might be perceived as difficult spaces. For these purposes we have worked on a layout across the five floors which would display design, fashion, craft, photography and architecture.

The varied heights and sizes of these galle- 
ries give an exciting range of display space, from the intimate to the monumental. Part of the space could function like a 3-D magazine, investigating latest style and technical developments and giving an editorial viewpoint. Other areas will be ideal for small monograph shows featuring new or emerging talent, while some floors will be ideal for more conventional exhibitions linked to education/ workshop spaces. These will provide the facilities for designers and other commentators to hold conversations and masterclasses with visitors to deepen their understanding of the design and manufacturing process. There will be no permanent collection in the Spiral; the programme will change frequently.

In fact, these studies have shown that the nature of the material to be shown in the Spiral lends itself easily to the innovative structure. More importantly, as the Museum intends to use the Spiral as a catalyst for change, this challenging building should provide the perfect environment in which to absorb and appreciate the V\&A's contemporary message. The idea behind the Spiral is to put visitors in the mood to be open-minded and creative when they get inside, helping to provide the impetus for the experiences within.

Above the five gallery floors are two linked floors for refreshment. The top floor has an amazing window that allows views across the roofscape of the V\&A and on into the West End of London. This is where the Light Bar will be situated, a meeting point for Londoners. Below will be linked rooms for events and functions.
Exhibition Road, with its three national museums, three post-graduate universities (The Royal College of Art, Imperial College of Science and Technology and the Royal College of Music) the Royal Albert Hall, the Royal Geographical Society and numerous other cultural and educational institutions is the most significant single cultural and educational centre in the world. Over recent years, heavy investment of public money in the Tate, the British Museum and other centres in London has pulled the centre of gravity in London to the centre and east of London, yet South Kensington remains the most visited museum site in the UK, with approximately eight million visitors per year. The building of the Spiral will symbolise its renewal and its contemporary relevance.

\section{REFERENCES}

Burton, Anthony, 'Vision \& Accident; The Story of the Victoria \& Albert Museum' 1999, V\&A Publications

Physick, John, 'The Victoria \& Albert Museum; The History of its Building' 1982, V\&A Publications

Gwyn Miles

Director of Projects \& Estate

Adr: Victoria and Albert Museum,

South Kensington, London SW7 2RL England

Fax: +44207942 2439

E-mail:g.miles@vam.ac.uk 


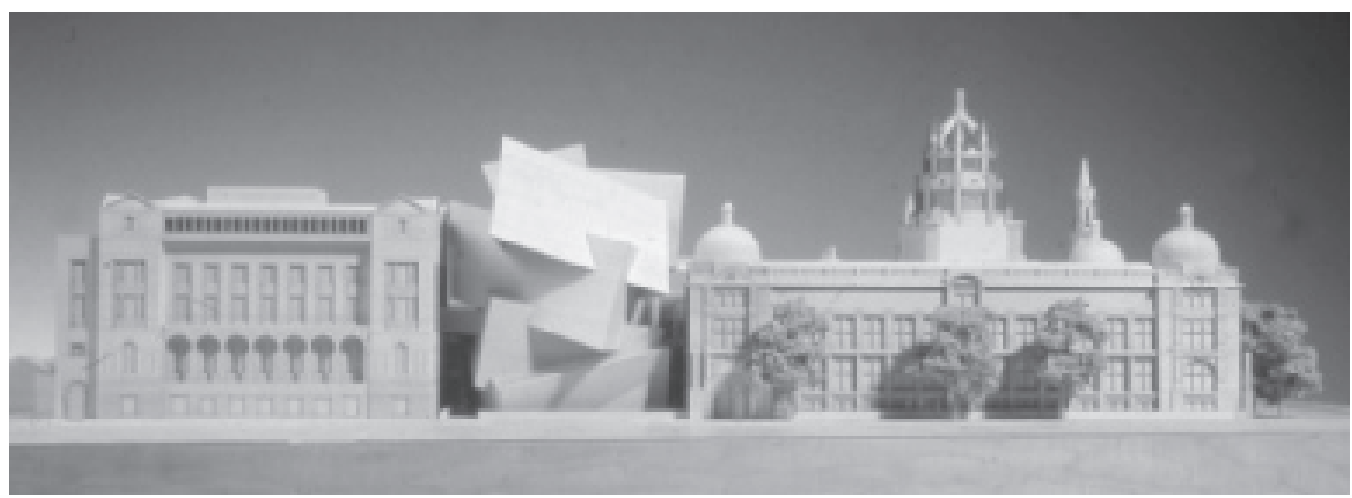

V\&A Museum model - Spiral seen from Exhibition Road.

Model made 2002, Photograph: Andrew Putter 2002.

Photo montage showing the same view. (C) Miller Hare 2001.

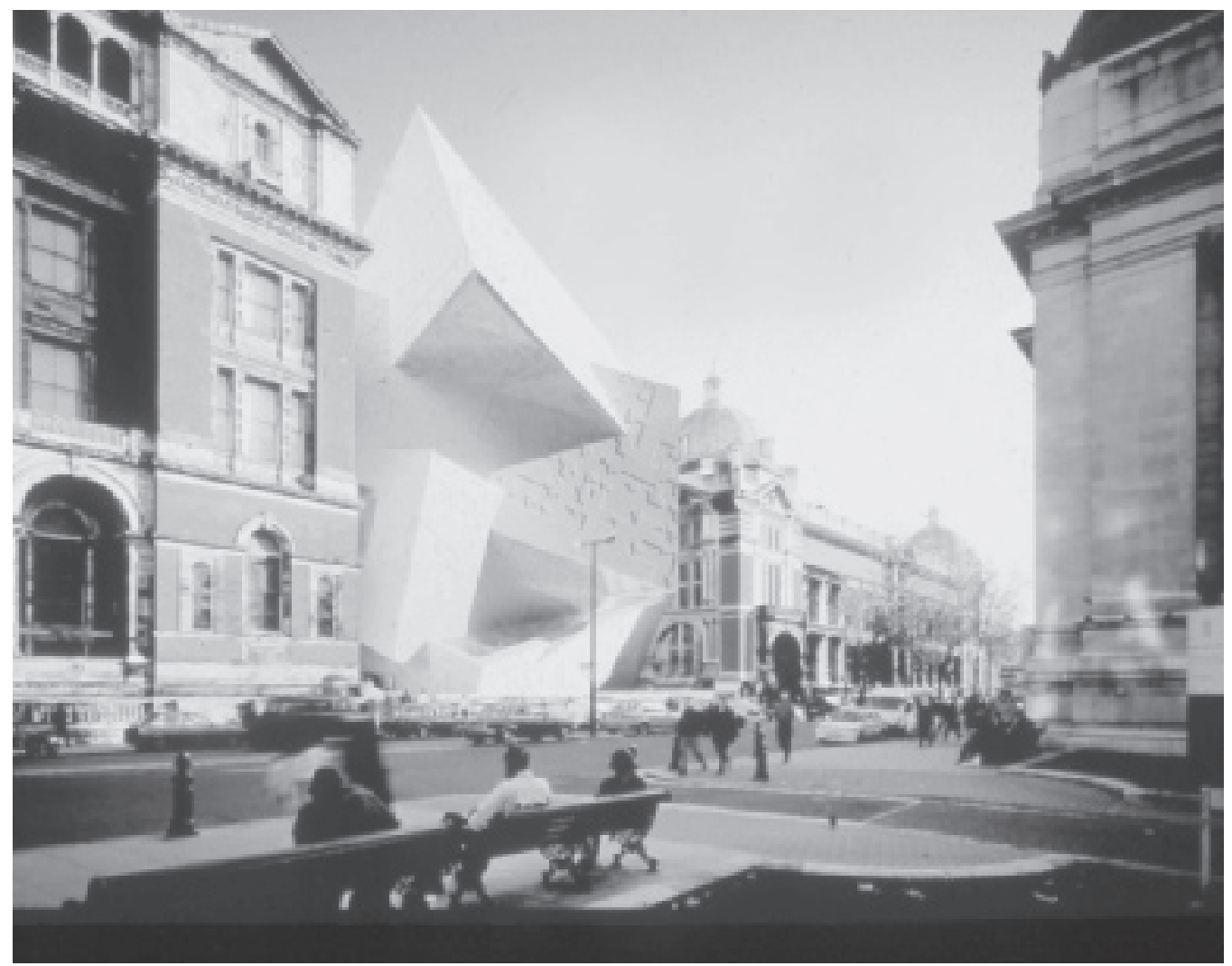

